\title{
Research on Metastable Structures Using High Energy Ball Milling at North Carolina State University (Overview)
}

\author{
C. C. Koch \\ Materials Science and Engineering Department, North Carolina State University, \\ Raleigh, N. C. 27695-7907, USA
}

\begin{abstract}
This paper reviews the research of the author's group at North Carolina State University over the last ten years in the field of metastable materials prepared by mechanical attrition. A brief historical perspective of the author on the beginnings of this sub-field is presented. Much of the research discussed is devoted to the crystalline-to-amorphous phase transformation induced by mechanical attrition. This includes mechanical alloying (MA) where dissimilar powders react and material transfer occurs. Equilibrium structures prepared by MA are also discussed. Amorphization by mechanical milling (MM), where a single composition (e.g. intermetallic compound) is milled requires the accumulation of defects to induce the transformation. It is concluded that anti-site chemical disorder and nanocrystalline grain boundaries are the important defects in this regard.

A brief description of studies on MM of normally immiscible systems is presented. Non-equilibrium solid solubilities can be achieved by MM of systems such as Ge-Sn and Si-Sn.

The paper concludes with a summary of recent work on nanocrystalline materials prepared by ball milling. The questions of 1) the mechanism for synthesis of nanocrystalline microstructures, and 2) the thermal stability of such microstructures are discussed.
\end{abstract}

(Received October 11, 1994)

Keywords: mechanical alloying, mechanical milling, solid state amorphization, immiscible alloy systems, nanocrystalline materials, intermetallic compounds

\section{Introduction/Historical}

My interest in the possibility of using mechanical attrition to prepare amorphous alloys was stimulated by my participation in a Panel on Amorphous Materials held in Monterey, California in 1980 under the auspices of the Council on Materials Sciences, for the Division of Materials Sciences, U.S. Department of Energy. It was suggested at this meeting-by Professor Bill Giessen-and documented in the Report of the Panel ${ }^{(1)}$ that mechanical alloying (MA) was a possible synthesis technique for amorphization which had not been explored. In 1983, before I left Oak Ridge National Laboratory for North Carolina State University, I decided to test this concept. I selected an easy glass forming alloy system $\mathrm{Ni}-\mathrm{Nb}$, and an average composition of $\mathrm{Ni}_{60} \mathrm{Nb}_{40}$. Starting with elemental $\mathrm{Ni}$ and $\mathrm{Nb}$ powders, a Spex 8000 shaker mill was used and X-ray diffraction measurements were carried out on powder samples after milling intervals of onehour. The diffraction lines broadened with milling time and eventually a diffraction pattern typical of amorphous $\mathrm{Ni}_{60} \mathrm{Nb}_{40}$ was observed as illustrated in Fig. 1. Differential scanning calorimetry (DSC) measurements on the mechanically alloyed (MA) $\mathrm{Ni}_{60} \mathrm{Nb}_{40}$ powders revealed an exothermic crystallization peak comparable to that for amorphous liquid quenched $\mathrm{Ni}_{60} \mathrm{Nb}_{40}$. Repeating the milling in a pure $\mathrm{He}$ atmosphere such that the oxygen contamination was reduced from 3.4 mass $\%$ for the samples milled in air to 0.46 mass $\%$ resulted in a crystallization temperature essentially identical to that for liquid quenched $\mathrm{Ni}_{60} \mathrm{Nb}_{40}$. In the process of preparing a paper to report these results ${ }^{(2)} \mathrm{I}$ became aware of the earlier work of A. E. Yermakov and his coworkers who had demonstrated amorphization of several Y-Co compounds, i.e. $\mathrm{YCo}_{3}, \mathrm{Y}_{2} \mathrm{Co}_{7}, \mathrm{YCo}_{5}$, and $\mathrm{Y}_{2} \mathrm{Co}_{17}^{(3)}$ and Gd-Co compounds ${ }^{(4)}$ by milling in a centrifugal planetary mill. As is now apparent these results represent the amorphization of a single phase intermetallic which we may refer to as amorphization by "mechanical milling" (MM) as opposed to amorphization of dissimilar powders-MAwhich involves material transfer. I had previously

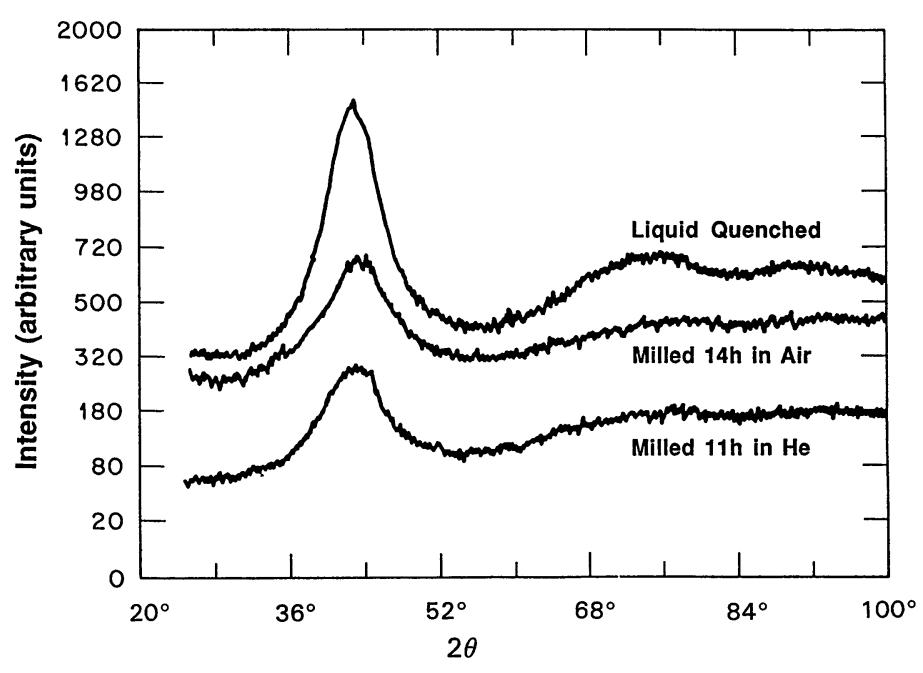

Fig. 1 Comparison of $\mathrm{X}$-ray diffraction patterns for amorphous liquid quenched $\mathrm{Ni}_{60} \mathrm{Nb}_{40}$ with $\mathrm{MA} \mathrm{Ni} \mathrm{Nb}_{60} \mathrm{Nb}_{40}$ either milled $14 \mathrm{~h}$ in air or $11 \mathrm{~h}$ in helium. 
received copies of several Ph.D. theses from Stanford University on the subject of MA from Dr. Warren Oliver, a recent Stanford graduate. The thesis of R. L. White ${ }^{(5)}$ was concerned with fabrication of superconducting $\mathrm{Nb}_{3} \mathrm{Sn} / \mathrm{Cu}$ composites by MA and powder consolidation methods. During MA of $\mathrm{Nb}$ and $\mathrm{Sn}$ it was noted in passing that after long milling times XRD patterns typical for an amorphous structure were observed in the asmilled powder. Since the focus of this work was the superconducting properties of the $\mathrm{Nb}_{3} \mathrm{Sn} \mathrm{A} 15$ phase after thermo-mechanical processing of the powder the observation of amorphization was not reported in the literature publication of this research. We now know that amorphous $\mathrm{Nb}_{3} \mathrm{Sn}$ forms by first formation of the $\mathrm{A} 15 \mathrm{Nb}_{3} \mathrm{Sn}$ phase by MA of elemental $\mathrm{Nb}$ and $\mathrm{Sn}$ followed by amorphization of the A15 compound by continued milling ${ }^{(6)}$. Therefore, we can say that the amorphization of $\mathrm{Ni}_{60} \mathrm{Nb}_{40}$ was the first example of amorphization of elemental powder mixtures by MA. Also in 1983 Schwarz and Johnson $^{(7)}$ observed amorphization by solid state diffusion between thin film multilayer sandwiches of $\mathrm{La}$ and $\mathrm{Au}$. Amorphization of $\mathrm{Zr}_{3} \mathrm{Rh}$ by hydrogenation was also discovered by Yeh et al. ${ }^{(8)}$ in 1983 . These reports stimulated increased interest in solid state amorphization and the use of ball milling as a non-equilibrium processing technique. However, at the Third International Conference on the Structure of Non-Crystalline Materials held in Grenoble, France July, 1985 there was still a great deal of skepticism regarding whether amorphization had really been achieved in our experiments ${ }^{(9)}$ on ball milling of $\mathrm{Nb}-$ $\mathrm{Sn}$ and $\mathrm{Nb}-\mathrm{Ge}$ alloys. Our paper was the only one on this subject presented at the conference. As more researchers entered this field it became clear that mechanical attrition was a new method, with a different, if unknown, mechanism, to produce metastable-particularly amorphousstructures. This research area has since blossomed into an important component of studies of metastable materials and plays a prominent role in international conferences on such topics. Several international conferences have now been devoted to the subject.

As requested by Profs. Shingu and Watanabe, my contribution to this special issue of Materials Transactions, JIM on Mechanical Alloying will be very personal in concentrating on the research of my group at North Carolina State University.

The organization of the paper will follow contributions our group have made to the topics of: 1) mechanics/modeling of the ball milling process, 2) equilibrium phases produced by MA, 3) amorphization by MA, 4) amorphization by MM, 5) milling of immiscible systems, and 6) nanocrystalline materials by ball milling.

\section{Mechanics/Modeling of the Ball Milling Process}

The kinetics of ball milling in a Spex shaker mill were modelled by McDermott ${ }^{(9)}$ and Davis et al. ${ }^{(10)}$. A computer simulation of the mechanics of this mill during operation was constructed to gain insight into the collision process as related to mechanical alloying/milling. The model consists of a simplified version of the movements of the vial combined with the inferred ball movements based on classical mechanics and analytic geometry. The vial motion was recorded on videotape after slowing its apparent velocity by use of a high precision stroboscope. This videotape was then analyzed by a "motion analysis" computer translation system. This converted the analog motion of the vial into digital coordinate displacements and velocities based on appropriate time constants of length calibrations. The ball motion was studied by observation through a transparent lucite vial. If any two balls were within one diameter of their loci, or any one ball was within one radius of the vial interior surface an impact was recorded, the ball impact dissipated kinetic energy, and mean free paths were recorded, and the ball's direction and velocity adjusted based on geometry of collision, vial impulse, and gravitational effects. The geometric and kinetic energy values were adjusted based on the restitution of the powder-coated steel balls, as determined by separate experiments.

Some results of this model are presented in Tables 1 and 2. Table 1 shows the number of impacts occurring for 0.5 and 1.0 seconds of mill operation with several different numbers of balls. The vast majority of impacts fall in the range of energy dissipated during the collision of $10^{-3}$ to $10^{-2} \mathrm{~J}$. This energy range of impacts predicts a ball velocity of $\leq 6 \mathrm{~m} \cdot \mathrm{s}^{-1}$ and using the expression and

Table 1 Number of impacts for various ball and kinetic energy values.

\begin{tabular}{lccccc}
\hline \hline $\begin{array}{l}\text { Number of } \\
\text { balls used } \\
\text { (2 g each) }\end{array}$ & \begin{tabular}{c}
\multicolumn{5}{c}{ Kinetic energy of impact joules } \\
to $10^{-7}$
\end{tabular} & $\begin{array}{c}10^{-2} \\
\text { to } 10^{-3}\end{array}$ & $\begin{array}{c}10^{-3} \\
\text { to } 10^{-2}\end{array}$ & $\begin{array}{c}10^{-2} \\
\text { to } 10^{-1}\end{array}$ & $\begin{array}{r}10^{-1} \\
\text { to } 1.0\end{array}$ \\
\hline \multicolumn{2}{l}{ Mill operation for 0.50 sec. } & & & \\
\hline 5 & 0 & 43 & 297 & 3 & 0 \\
10 & 0 & 78 & 505 & 13 & 1 \\
15 & 4 & 124 & 928 & 24 & 0 \\
Mill operation for 1.00 sec. & & & & \\
\hline 5 & 0 & 78 & 612 & 3 & 0 \\
10 & 0 & 148 & 1201 & 13 & 2 \\
15 & 4 & 229 & 1873 & 24 & 0 \\
\hline \hline
\end{tabular}

Table 2 Number of ball impacts for various impact angles and 15 balls.

\begin{tabular}{ccc}
\hline $\begin{array}{c}\text { Impact angle } \\
\text { (degrees) }\end{array}$ & $\begin{array}{c}\text { Number impacts } \\
(0.50 \text {-sec. operation) }\end{array}$ & (1.00-sec. operation) \\
\hline 1 to 10 & 268 & 508 \\
11 to 20 & 251 & 491 \\
21 to 30 & 214 & 439 \\
31 to 40 & 107 & 227 \\
41 to 50 & 7 & 7 \\
51 to 60 & 113 & 233 \\
61 to 70 & 108 & 213 \\
71 to 80 & 4 & 4 \\
81 to 90 & 8 & 8 \\
\hline
\end{tabular}

$90 \mathrm{deg}$ is direct head-on impact 0 to $10 \mathrm{deg}$ is a glancing impact. 
materials of Schwarz and $\operatorname{Koch}^{(11)}$ a calculated increase in local powder temperature; $\Delta T \leq 112 \mathrm{~K}$. High energy impacts $(\sim 0.1 \mathrm{~J})$ predict a maximum ball velocity of $\sim 19$ $\mathrm{m} \cdot \mathrm{s}^{-1}$ and a $\Delta T \approx 350 \mathrm{~K}$. However, Table 2 illustrates that only about $0.4 \%$ of the impacts are within $10^{\circ}$ of a head-on collision. After 15 min of milling only about $1 \%$ of the total impacts have the capability of producing $\Delta T$ values between 112 and $350 \mathrm{~K}$.

While more extensive modeling efforts have been carried out in recent years (e.g. Ref. (12)), aspects of this early work have been used to help define concepts such as ball impact angle frequency and local temperature rise.

In an effort to obtain an estimate of the temperatures attained in the powders during milling, Davis et al. ${ }^{(10)}$ studied the tempering response of as-quenched tetragonal ("fresh") martensite in an Fe-1.2 mass \%C alloy. Differential scanning calorimetry (DSC) was used to follow the decomposition of the martensite as $\varepsilon$-carbide and then $\mathrm{Fe}_{3} \mathrm{C}$ precipitates from the martensite matrix at about $418 \mathrm{~K}$ and $575 \mathrm{~K}$ respectively. The percent of $\mathrm{Fe}_{3} \mathrm{C}$ converted from the martensite was calibrated by separate annealing experiments, and literature results, and in this way DSC could monitor the amount of martensite decomposition occurring during milling. This experiment provided an upper limit of $275^{\circ} \mathrm{C}$ for the temperature the powders reached during milling. The defects (dislocations and point defects) which are presumably introduced during milling may enhance carbon diffusivity, create heterogeneous nucleation sites, etc. and accelerate the $\mathrm{Fe}_{3} \mathrm{C}$ precipitation reaction such that it could occur at lower temperature. Ball milling is unusual in that plastic deformation can be introduced in nominally brittle materials like $\mathrm{Fe}-1.2$ mass $\% \mathrm{C}$ martensite which normally fracture in the elastic regime under uniaxial deformation. The upper limit to the temperature increase due to milling experimentally obtained in this work is comparable to those values estimated by calculations from several models ${ }^{(13)}$. Therefore, both modeling and experiments suggest the temperature rises experienced by powders during milling at "conventional" energy levels (e.g. in a Spex shaker mill) are modest, typically $100-300 \mathrm{~K}$.

\section{Equilibrium Phases Produced by Mechanical Alloying}

While most scientific attention in the use of mechanical attrition has been focused on metastable materials it is also possible to synthesize equilibrium phases by this technique. This has been clearly demonstrated in several systems which exhibit complete solid solubility as well as in systems with intermediate phases.

Ge and Si exhibit complete solid solubility which would be expected since they are isoelectronic, have the same crystal structure (diamond cubic) and their lattice parameters differ by only about $4.0 \%$. Ge and $\mathrm{Si}$ are, however, both nominally brittle at room temperature and they were taken as components in a study of the MA of brittle materials ${ }^{(10)}$. Davis and Koch $^{(14)}$ demonstrated that ball milling $\mathrm{Ge}$ and $\mathrm{Si}$ powder together resulted in material transfer and alloying. The lattice parameters of $\mathrm{Ge}$ and $\mathrm{Si}$ move together with milling time and after about $4 \mathrm{~h}$ to $5 \mathrm{~h}$ merge into a single lattice parameter for the Ge-Si solid solution. This change in lattice parameter is illustrated in Fig. 2 for a Ge-72 at.\%Si alloy. An example of another equilibrium solid solution prepared by $\mathrm{MA}$ is $\mathrm{Cu}-\mathrm{Ni}^{(15)}$.

Intermediate phases and intermetallic compounds have been synthesized from the pure components by MA in several alloy systems. The equilibrium Hume-Rothery electron compounds, $\beta^{\prime}$-brass ${ }^{(16)}, \gamma$-brass ${ }^{(9)}$, and $\varepsilon$-brass ${ }^{(9)}$, were synthesized by MA of pure $\mathrm{Cu}$ and pure $\mathrm{Zn}$ powders mixed in the proper proportions. Thus the equilibrium intermediate phases were synthesized by MA of the elemental components. In the case of $\beta^{\prime}$-brass, evidence for fcc deformation-induced martensite was observed by $\mathrm{X}$-ray diffraction as a minor phase in the $\beta^{\prime}$-brass matrix. A nonequilibrium phase was therefore also present as a result of the plastic deformation which is an integral part of MA. Kim ${ }^{(17)}$ and Koch and $\mathrm{Kim}^{(18)}$ synthesized the intermetallic compounds $\mathrm{Nb}_{4} \mathrm{Ge}, \mathrm{Nb}_{5} \mathrm{Ge}_{3}$ and $\mathrm{NbGe}_{2}$ in the $\mathrm{Nb}-\mathrm{Ge}$ system and $\mathrm{Nb}_{3} \mathrm{Sn}$ in the $\mathrm{Nb}-\mathrm{Sn}$ system. On continued milling, the $\mathrm{Nb}_{4} \mathrm{Ge}$ and $\mathrm{Nb}_{3} \mathrm{Sn}$ compounds become amorphous.

\section{Amorphization by Mechanical Alloying}

The initial studies of amorphization of $\mathrm{Ni}_{60} \mathrm{Nb}_{40}$, described in the Introduction, were extended to the entire $\mathrm{Ni}-\mathrm{Nb}$ alloy system ${ }^{(19)}$. Amorphous $\mathrm{Ni}_{x} \mathrm{Nb}_{1-x}$ alloy powder was synthesized in the range $0.20<x<0.79$ by mechanical alloying. This range is larger than that reported for conventional liquid-quenched and ion-beam-mixed alloys but similar to that for alloys produced by picosecond pulsed laser quenching and rf sputtering. With mechanical alloying, the solubility limits of $\mathrm{Ni}$ in bcc $\mathrm{Nb}$ and $\mathrm{Nb}$ in fcc $\mathrm{Ni}$ have been extended to about $10 \% \mathrm{Ni}$ and $10 \% \mathrm{Nb}$, which are significantly larger than the solubilities predicted by the phase diagram for $1000^{\circ} \mathrm{C}(3.5$ at. $\%$ $\mathrm{Ni}, 4.2$ at. $\% \mathrm{Nb})$. The crystallization temperature and activation energy for crystallization of the $\mathrm{Nb}$-rich compositions $\left(\mathrm{Ni}_{20} \mathrm{Nb}_{80}-\mathrm{Ni}_{50} \mathrm{Nb}_{50}\right)$ are higher than the $\mathrm{Ni}$-rich

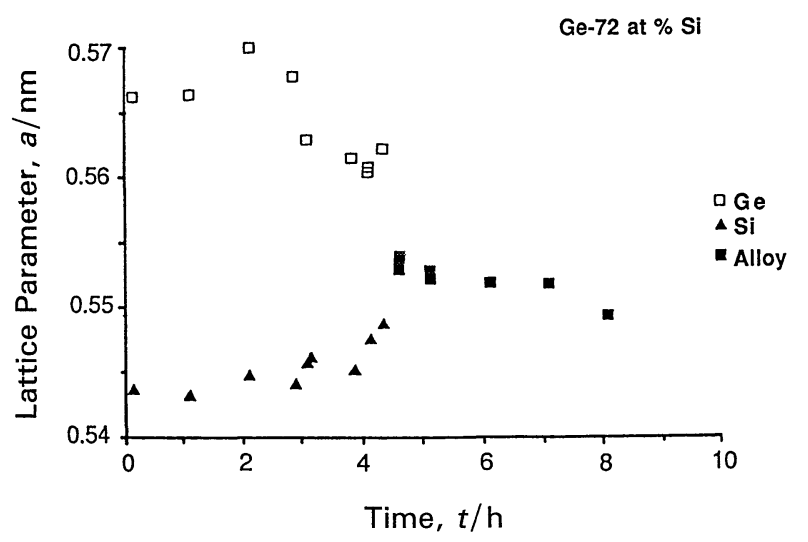

Fig. 2 Lattice parameter vs. milling time for $\mathrm{Si}, \mathrm{Ge}$, and $\mathrm{Si}(\mathrm{Ge})$ alloy at a composition of $\mathrm{Si}-28$ at. $\% \mathrm{Ge}$. 
compositions $\left(\mathrm{Ni}_{65} \mathrm{Nb}_{35}-\mathrm{Ni}_{79} \mathrm{Nb}_{21}\right)$. Both crystallization temperature and activation energy exhibited a maximum at the eutectic composition ( $\sim 60$ at. $\% \mathrm{Ni})$. The products after crystallization in the range of $\mathrm{Ni}_{20} \mathrm{Nb}_{80}-\mathrm{Ni}_{50} \mathrm{Nb}_{50}$ include a non-equilibrium $\eta$-phase- $\mathrm{Nb}_{2} \mathrm{NiO}_{x}(x=0.046-$ 0.092). The effect of oxygen was investigated. Oxygen accelerates the amorphization rate but decreases the crystallization temperature and activation energy for crystallization of the amorphous $\mathrm{Ni}-\mathrm{Nb}$ powders.

Another easy-glass-forming alloy system which we have studied in some detail is the $\mathrm{Ni}-\mathrm{Zr}$ system ${ }^{(20)}$. Amorphous $\mathrm{Ni}-\mathrm{Zr}$ alloys were synthesized by mechanical alloying of powder mixtures with different crystalline states: (1) mixtures of pure elemental crystalline powders with intermetallic powders, (2) mixtures of intermetallic powders. The results obtained are summarized as follows:

Amorphous $\mathrm{Ni}_{x} \mathrm{Zr}_{1-x}$ alloy powders were synthesized in the range $0.24<x<0.85$ by mechanical alloying. This range is larger than amorphous alloys produced by the melt-spinning technique or by mechanical alloying of elemental crystalline powders. A mixture of amorphous and crystalline phases formed in the composition range of $0.10<x<0.22$ and $x=0.90$.

The driving force for the amorphization of mixtures of intermetallics is believed to be either the steep rise in the free energy of the line compounds as material transfer moves their compositions off-stoichiometry, or the creation of a critical defect concentration in the intermetallic compounds.

The enthalpy and activation energy for crystallization of the MA Ni-Zr amorphous powders are lower than for melt-spun samples. The temperature for crystallization of the MA Ni-Zr amorphous powders is higher than the melt-spun samples in the composition range $\mathrm{Ni}_{20} \mathrm{Zr}_{80}$ to $\mathrm{Ni}_{33} \mathrm{Zr}_{67}$ and $\mathrm{Ni}_{40} \mathrm{Zr}_{60}$ to $\mathrm{Ni}_{60} \mathrm{Zr}_{40}$. Oxygen increases the crystallization temperature and activation energy for crystallization of the $\mathrm{Ni}_{40} \mathrm{Zr}_{60}$ and $\mathrm{Ni}_{50} \mathrm{Zr}_{50}$ amorphous powders. This is illustrated in Fig. 3. This effect of oxygen on crystallization temperature and activation energy for crystallization is just the opposite of its effect in $\mathrm{Ni}-\mathrm{Nb}$ alloys as described above. Therefore, one can't generalize on

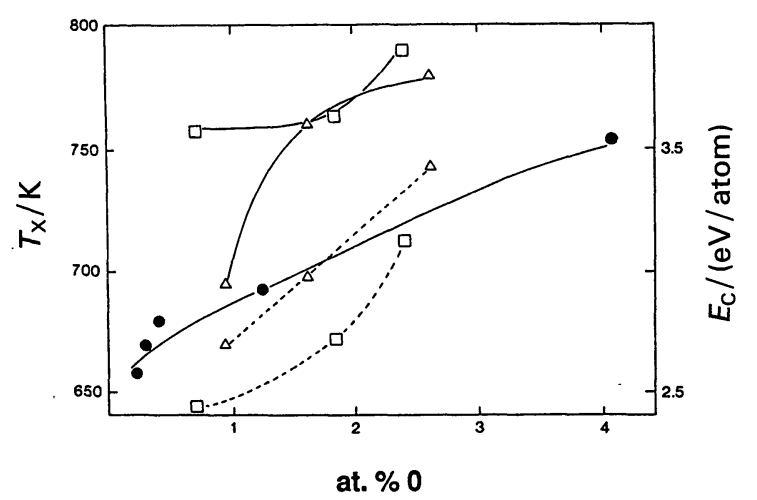

Fig. 3 Temperature $\left(T_{\mathrm{x}}-\right)$ and activation energy $\left(E_{\mathrm{c}} \cdots\right)$ for crystallization of $(\triangle) \mathrm{Ni}_{40} \mathrm{Zr}_{60},(\bullet) \mathrm{Ni}_{33} \mathrm{Zr}_{67}$, and $(\square) \mathrm{Ni}_{50} \mathrm{Zr}_{50}$ amorphous powders as a function of oxygen content. the effect of oxygen on promoting or retarding amorphization. It is apparently very material dependent.

While new "amorphous" materials are typically revealed by diffraction experiments, there is often ambiguity in distinguishing between a "truly" amorphous-i.e. continuous, non periodic-structure and a microcrystalline structure.

In a diffraction experiment of such an "amorphous" structure, the intensity but not the phase of the scattered radiation is measured. Fourier inversion of these data can yield only the radial distribution function of the structure which cannot uniquely specify the atomic positions. To determine the structure, the experimentally determined radial distribution function must be compared with radial distribution functions calculated from the structural models being considered ${ }^{(21)}$ (e.g. microcrystalline vs. continuous dense random packing). While the diffraction patterns of most amorphous metallic alloys can be better fit by continuous dense random packing models $^{(21)}$ there are reports of microcrystalline structures (e.g. Ref. (22)). The problems of whether a new disordered material is "only" microcrystalline or "truly" amorphous is particularly acute for alloys synthesized by ball milling since the evolution of the disordered structure often involves the broadening of diffraction lines with milling time ${ }^{(2)}$. This implies a fragmentation of crystallites with milling time that might lead to a microcrystalline structure.

The appearance of a glass transition temperature, $T_{g}$, as determined by calorimetry, is strong evidence for a liquid-like and therefore "truly" amorphous structure. Jang and $\mathrm{Koch}^{(23)}$ have observed $T_{\mathrm{g}}$ 's in amorphous $\mathrm{Cu}_{1-x} \mathrm{Zr}_{x}$ alloys prepared by either MA of elemental $\mathrm{Cu}$ and $\mathrm{Zr}$ powder or $\mathrm{MM}$ of $\mathrm{CuZr}$ and $\mathrm{Cu}_{3} \mathrm{Zr}_{2}$ intermetallic compound power. Differential scanning calorimeter (DSC) traces are shown in Fig. 4 for $\mathrm{Cu}_{40} \mathrm{Zr}_{60}, \mathrm{Cu}_{50} \mathrm{Zr}_{50}$ and $\mathrm{Cu}_{60} \mathrm{Zr}_{40}$ alloys amorphized by MA. Endothermic $T_{\mathrm{g}}$ 's are clearly observed prior to the larger exothermic crystallization peaks. It was found that if the iron and oxygen impurities which can occur in amorphous $\mathrm{Cu}_{1-x} \mathrm{Zr}_{x}$ alloys prepared by MA or MM are accounted for, essentially identical $T_{\mathrm{g}}$ values to those of amorphous rapidly solidified material are observed. The MA/MM samples had small ( 0.25 at.\%) or no Fe impurity contamination. If the $T_{\mathrm{g}}$ vs. \% oxygen data (albeit limited) for $\mathrm{MA} / \mathrm{MM}$ and rapidly solidified $\mathrm{CuZr}$ are extrapolated to zero \% oxygen, a common $T_{\mathrm{g}}$ of about $670 \mathrm{~K}$ is obtained in each case.

The above evidence clearly indicates that amorphous alloys prepared by MA or MM can be "truly" amorphous as opposed to microcrystalline-that is they can be "metallic glasses".

It is generally believed that the mechanism for amorphization by MA involves an extension of the mechanism for "a solid state amorphization reaction" (SSAR) between films of two crystalline pure metals that have a large negative heat of mixing in the amorphous state and a large asymmetry in the component diffusivities ${ }^{(7)}$. Many of the same alloy systems which undergo SSAR also are 


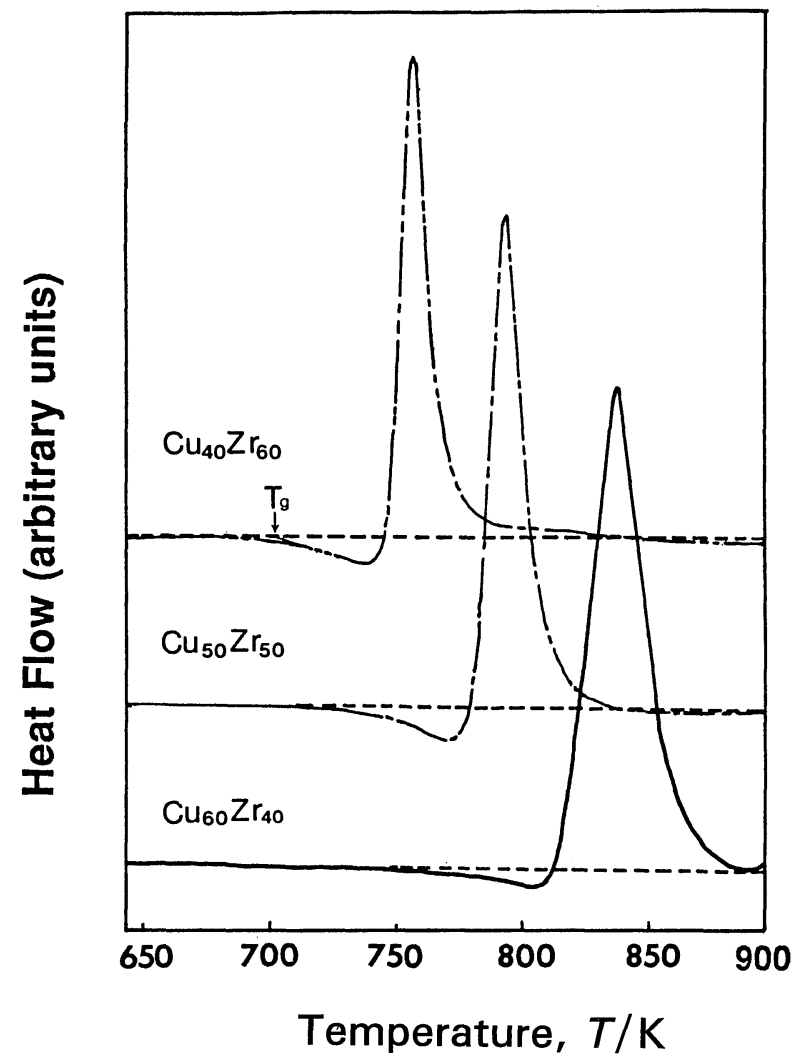

Fig. 4 DSC traces for MA Cu $\mathrm{Mu}_{1-x} \mathrm{Zr}_{x}$ alloys showing endothermic glass transitions and exothermic crystallization peaks.

found to amorphize by MA.

On the other hand, the defects created by the severe plastic deformation induced by milling would be expected to influence both the thermodynamics and kinetics of the crystalline-to-amorphous transformation by MA. Thus a one-to-one comparison between SSAR of diffusion couples and amorphization by MA might not be general. In fact, it has been shown that several alloys can be amorphized by MA but not by SSAR of thin film diffusion couples. These included $\mathrm{Nb}_{50} \mathrm{Al}_{50}{ }^{(25)}$ and $\mathrm{Nb}_{75} \mathrm{Ge}_{25}{ }^{(18)(26)}$. In the case of $\mathrm{Nb}_{75} \mathrm{Ge}_{25}$ the mechanism for amorphization can be classified with amorphization of intermetallic compounds by $\mathrm{MM}$, since for $\mathrm{Nb}$ and $\mathrm{Ge}$ powders MA first forms the A15 structure $\mathrm{Nb}_{3} \mathrm{Ge}$ compound which subsequently transforms to the amorphous alloy with continued milling. A clear example of this behavior was observed in the $\mathrm{Nb}-\mathrm{Sn}$ system $^{(6)}$. Elemental $\mathrm{Nb}$ and Sn powders were milled together at the composition $\mathrm{Nb}_{75} \mathrm{Sn}_{25}$. As a function of milling time the X-ray diffraction patterns change from a mixture of $\mathrm{Nb}$ and $\mathrm{Sn}$ lines to lines of the crystalline A15 structure and then finally to the pattern for an amorphous structure. The reaction $A_{n}+B_{m} \rightarrow$ Cryst. $A_{n} B_{m} \rightarrow$ amorph. $A_{n} B_{m}$ with milling time is in effect a variation of $\mathrm{MM}$ by first producing the equilibrium intermetallic compound which can then be amorphized.

\section{Amorphization by Mechanical Milling (MM)}

In order for amorphization to occur by MM of an equilibrium intermetallic compound, the free energy of the crystalline compound must be raised to that of the corresponding amorphous alloy. Defects introduced by the deformation during milling must be responsible for raising the free energy of the crystalline compound. Energy can be stored in a deformed material in the form of defects such a vacancies, interstitials, dislocations, grain boundaries, and atomic disorder. The critical question in this regard is: what defects can provide the required increase in free energy? While free energy differences between the crystalline compound and the amorphous alloy are typically $5-20 \mathrm{~kJ} \cdot \mathrm{mol}^{-1}$, the stored energy of deformation from conventional deformation processes is rarely more than about $1-2 \mathrm{~kJ} \cdot \mathrm{mol}^{-1}$ or less than or equal to $5 \%$ of the heat of fusion ${ }^{(27)}$. A maximum value for the stored energy associated with a very high dislocation density of about $10^{14} \mathrm{~cm}^{-2}$ in cold-rolled $\mathrm{NiTi}$ was estimated to be $2.2 \mathrm{~kJ} \cdot \mathrm{mol}^{-1}$ by Koike et al. ${ }^{(28)}$. Amorphization in intermetallics by the plastic deformation supplied by ball milling is analogous to amorphization in intermetallics by irradiation with energetic particles such as electrons, ions, or neutrons. As with amorphization by irradiation it is likely that anti-site disordering can provide sufficient energy for amorphization of intermetallics by milling in some cases. Seki and Johnson $^{(29)}$ have suggested that the amorphization of the $\mathrm{CuTi}_{2}$ intermetallic by ball milling was driven mainly by the energy stored in antiphase domain boundaries. Contributions from dislocations and grain boundaries were estimated to be $1 \mathrm{~kJ} \cdot \mathrm{mol}^{-1}$ and $1.6-2.9 \mathrm{~kJ} \cdot \mathrm{mol}^{-1}$ respectively. The remainder of the stored energy required for amorphization (the enthalpy of crystallization $=11$ $\mathrm{kJ} \cdot \mathrm{mol}^{-1}$ ) was believed to come from the disordering at antiphase boundaries. Bakker and coworkers ${ }^{(30)}$ have argued that anti-site chemical disorder is the main source of energy storage in ball-milled intermetallics. They suggest that amorphization results if the free energy of the disordered compound exceeds the free energy of the amorphous state. However, Jang and $\mathrm{Koch}^{(31)}$ observed the long-range order (LRO) parameter to decrease to zero at milling times a factor of ten shorter than the time at which partial amorphization was first observed in $\mathrm{Ni}_{3} \mathrm{Al}$. Similarly, Cho and $\mathrm{Koch}^{(32)}$ determined that the LRO in ball-milled $\mathrm{Nb}_{3} \mathrm{Sn}$ disappeared after about $1 \mathrm{~h}$ of milling while amorphization was not initiated until 5-6 h of milling, as illustrated in Fig. 5. It was suggested that the additional stored energy required for the crystallineto-amorphous transformation in $\mathrm{Nb}_{3} \mathrm{Sn}$ came from the grain boundary energy of the fine nanocrystalline grain structure that evolved during milling of the disordered compound.

In order to clarify these ideas the following intermetallic compounds were studied which may or may not exhibit amorphization by $\mathbf{M M}^{(33)}$. These compounds were: 1) $\mathrm{Ni}_{3} \mathrm{Si}$-no amorphization by $\mathrm{MM}$ 


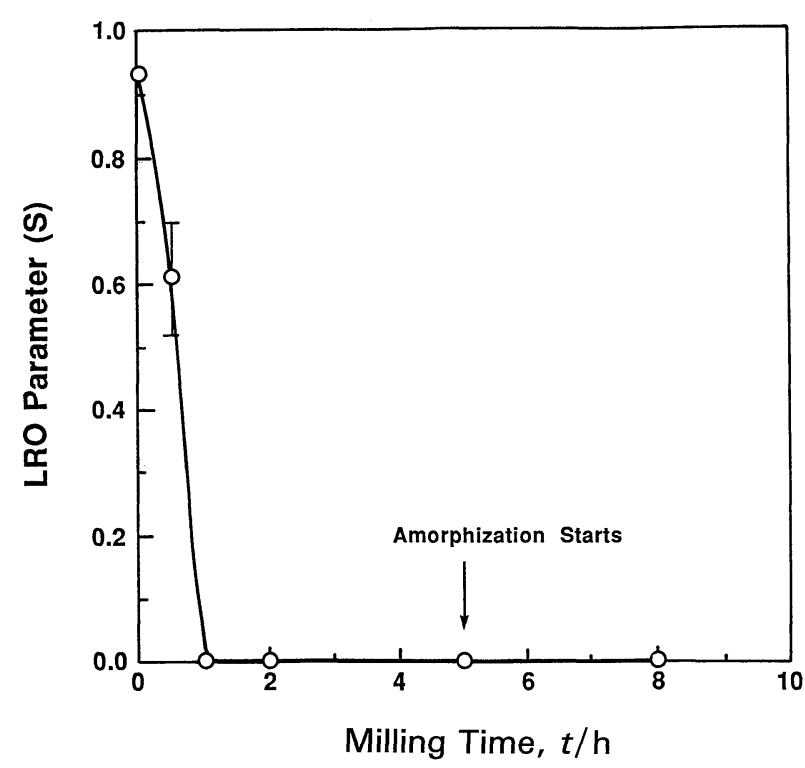

Fig. 5 Long-range-order (LRO) parameter S vs. milling time for $\mathrm{Nb}_{3} \mathrm{Sn}$.

2) $\mathrm{Ni}_{3} \mathrm{Al}$-partial (slight) amorphization by $\mathrm{MM}$

3) $\mathrm{Nb}_{3} \mathrm{Sn}$-complete amorphization by $\mathrm{MM}$

4) $\mathrm{CoZr}-$ complete amorphization by MM.

The structural evolution with milling time was studied in these compounds. Estimates of the free energy differences $\Delta G^{\mathrm{a}-\mathrm{c}}$ between the crystalline and amorphous phases for each compound were made. Similarly, the magnitude of the possible energy supplied by anti-site disordering and the nanocrystalline grain boundary energy was estimated.

These estimates vary in reliability from relatively high for $\mathrm{CoZr}$ where experimental data and CALPHAD calculations are available, to low for $\mathrm{Nb}_{3} \mathrm{Sn}$ where estimates based on a modified Richard's Rule are the only available approximations for the energy differences between the ordered crystalline and amorphous phases. The estimates for the anti-site disordering energies were taken from either the enthalpy observed using DSC at milling times when disorder was complete, taken as $21-37 \%$ of the enthalpy of formation or from CALPHAD calculations. Enthalpies were converted to free energies by calculating the entropy of mixing for the ideal solution at $350 \mathrm{~K}$.

Nanocrystalline grain boundary energies were estimated from the observed grain sizes and data or estimates for grain boundary energies.

In spite of the large variations in the estimates for the various energy terms the results can be summarized for the compounds studied.

(1) $\mathrm{Ni}_{3} \mathrm{Si}$ : The sum of the anti-site disordering energy and the grain boundary energy is not sufficient to overcome the energy difference between the ordered crystalline and amorphous phases. This is consistent with no observation of amorphization.

(2) $\mathrm{Ni}_{3} \mathrm{Al}$ : The sum of the anti-site disordering energy and the grain boundary energy is comparable with or greater than $\Delta G^{\text {a-c }}$. However, since only partial amorphi- zation is observed in $\mathrm{Ni}_{3} \mathrm{Al}$, the accuracy of these energy values is suspect.

(3) $\mathrm{Nb}_{3}$ Sn: The sum of $\Delta G^{\text {disordering }}$ and $\Delta G^{\text {grain boundary }}$ is comparable with $\Delta G^{\mathrm{a}-\mathrm{c}}$. Complete amorphization is observed at milling times about five times longer than those where disordering is complete. These observations are consistent with the driving free energy for the crystallineto-amorphous phase transformation as the sum of the disordering and grain boundary energies.

(4) CoZr: Both $\Delta G^{\text {disordering }}$ and $\Delta G^{\text {grain boundary }}$ are large for CoZr and individually can overcome $\Delta G^{\mathrm{a}-\mathrm{c}}$. Since no experimental evidence exists for disordering (i.e. $S \approx 1.0$ ) up to and beyond the milling times when amorphization begins, it is concluded that the creation of the fine nanocrystalline grains in perfectly ordered $\mathrm{CoZr}$ drives the phase transformation.

It appears, then, from our research and that of others e.g. Ref. (34) that anti-site disorder and grain boundary energy of nanoscale grains are the important defects which can drive the crystalline-to-amorphous transformation by MM.

If indeed the mechanism for amorphization is due to increasing the free energy of the crystalline material by the introduction of defects such as anti-site chemical disorder or nanocrystalline grain boundaries, then intuitively it would be expected that lower milling temperatures, at which defect recovery is minimized, would favor amorphization by MM. However, Lee et al. ${ }^{(35)}$ observed enhanced amorphization kinetics at higher milling temperatures for $\mathrm{NiZr}_{2}$ intermetallic compound powder. In this case their milling energy remained constant while the mill temperature was independently varied from -180 to $200^{\circ} \mathrm{C}$. In contrast to these observations, Gaffet and Yousf ${ }^{(36)}$ and Chen et al. $^{(37)}$ have reported that higher milling temperatures retard amorphization of the compounds $\mathrm{Ni}_{10} \mathrm{Zr}_{7}$ and $\mathrm{Ni}_{11} \mathrm{Zr}_{9}$. Yamada and $\mathrm{Koch}^{(38)}$ have also recently observed slower amorphization kinetics of the NiTi compound as milling temperature is increased. Three milling temperatures in a Spex shaker mill were studied, namely $-190,60$, and $220^{\circ} \mathrm{C}$. The structural changes leading to amorphization were followed by Xray diffraction line broadening and TEM. It was concluded that the creation of a nanocrystalline grain structure and therefore a high defect density (the grain boundaries) drove the amorphization reaction. It was found that the nanocrystalline structure developed more rapidly at lower milling temperatures, as illustrated in Fig. 6 where grain size vs. milling time is plotted for the three milling temperatures. Subsequently, Pathak et al. ${ }^{(39)}$ studied the influence of milling temperature on the amorphization kinetics of the intermetallics NiTi, CoZr, and $\mathrm{NiZr}_{2}$. In all these cases, lower milling temperatures favored more rapid amorphization as illustrated in Fig. 7. The results for $\mathrm{NiZr}_{2}$ are in direct contrast to the observations of Lee et $a l .{ }^{(35)}$. The discrepancies between the above cited experiments point to a probable complex interaction of mill energy, mill temperature, and sample chemistry to produce a given structure/microstructure. More study of this topic appears to be needed. 


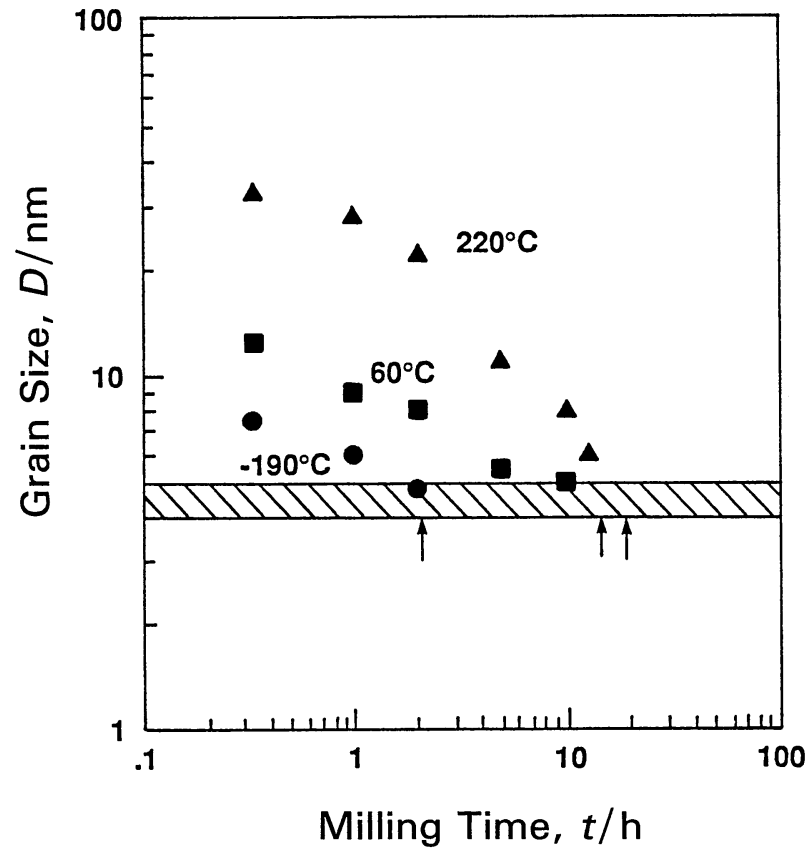

Fig. 6 Grain size versus milling time for NiTi at milling temperatures of $-190,60$, and $220^{\circ} \mathrm{C}$.

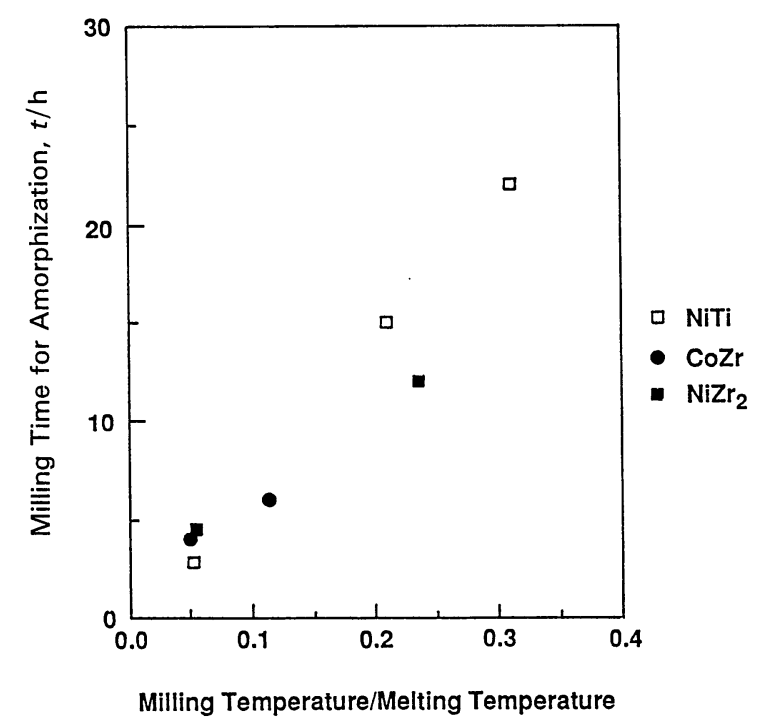

Fig. 7 Milling time for amorphization vs. normalized milling temperature for $\mathrm{CoZr}, \mathrm{NiTi}$, and $\mathrm{NiZr}_{2}$.

\section{Milling of Immiscible Systems}

A question regarding the phase distribution in mechanically milled immiscible systems is: what is the lower size distribution limit to which immiscible particles can be milled? Since in solid solution alloys, MA can result in alloying at the atomic level, very fine particle distributions might be attainable by MA immiscible components. Mechanical alloying has been applied to the immiscible systems $\mathrm{Ge}-\mathrm{Sn}, \mathrm{Al}-\mathrm{Ge}$, and $\mathrm{Ge}-\mathrm{Pb}$ with the goal of determining the limits of phase refinement ${ }^{(40)}$. Mechanical alloying was carried out for milling times up to $60 \mathrm{~h}$ under an air or argon atmosphere in a SPEX mixer/mill. Some tests were conducted with the milling vial cooled with a stream of liquid nitrogen. X-ray diffraction of powder taken at various milling times showed the systems remained as two-phase pure components and their precise lattice parameters remained constant with milling time, which indicated no alloying or contamination to the accuracy of the lattice parameter measurements. Optical microscopy, SEM, and transmission electron microscopy (TEM) were used to follow the progress of the microstructural refinement with milling time.

The average center-to-center nearest neighbor distance between dispersed Ge particles was measured by the above metallographic techniques. The logarithm of Ge interparticle distance exhibits an inverse linear dependence on milling time. After $32 \mathrm{~h}$ of milling, the average $\mathrm{Ge}$ interparticle distance was about $20 \mathrm{~nm}$. Stereology techniques determined that the Ge particles had a random Poison distribution throughout the Sn matrix. Further milling did not appear to significantly change the particle sizes or distributions so the limit of refinement was attained for the given milling conditions in this system. The mixing of these insoluble components by mechanical attrition is balanced by the demixing driven by the thermodynamics of the system, i.e., large positive heat of mixing. With sufficient mobility, the like atoms will segregate together. An order of magnitude estimate for this segregation, using $\sqrt{D t}$ as the characteristic diffusion distance, and ambient temperature diffusion coefflcients, was consistent with the microstructural observations.

A particularly interesting observation from the study of MM immiscible $\mathrm{Ge}-\mathrm{Sn}$ and Ge-Pb systems was the depression of the melting point of $\mathrm{Sn}$ or $\mathrm{Pb}$ with milling time and Ge concentration. The first observation of the melting point depression was noted in DSC scans for a Sn-45 vol. \% Ge mixture as a function of milling time ${ }^{(41)}$. The magnitude of the melting point depression, $\Delta T_{M}$, increased with milling time, that is, with refinement of the dispersion. Melting point depressions were defined from the DSC endotherms as $\Delta T_{\mathrm{M}}^{\text {peak }}$ and $\Delta T_{\mathrm{M}}^{\text {tail }}$ as illustrated in Fig. 8. The magnitudes of the $\Delta T_{\mathrm{M}}$ 's were found to reach constant values after $32 \mathrm{~h}$ of milling. After $32 \mathrm{~h}$ of milling the average diameters of the hard Ge particles embedded in the $\mathrm{Sn}$ (or $\mathrm{Pb}$ ) matrix were approximately $10 \mathrm{~nm}$ and were essentially unchanged by additional milling ${ }^{(42)}$. Calorimetric measurements indicated that the melting temperatures of $\mathrm{Sn}$ in these dispersions, even upon remelting after solidification, were depressed to values considerably below that, $T_{\mathrm{M}}^{\circ}$, of pure $\mathrm{Sn}$. For a Ge volume fraction $V_{\mathrm{Ge}}=0.455$ melting was observed to begin as low as $36^{\circ} \mathrm{C}$ below the equilibrium bulk melting temperature. It was concluded that the major contribution to the melting point depression, $\Delta T_{\mathrm{M}}$, comes from the nucleation of disorder/melting at the Ge/Sn interfaces. It was also found that as $V_{\mathrm{Ge}}$ was increased the measured enthalpy of melting per mass of total tin added, $\Delta H_{\mathrm{M}}$, decreased to levels well below that, $\Delta H_{\mathrm{M}}^{\circ}$, of pure bulk $\mathrm{Sn}$, and at $V_{\mathrm{Ge}}>0.81$ it was immeasurably 


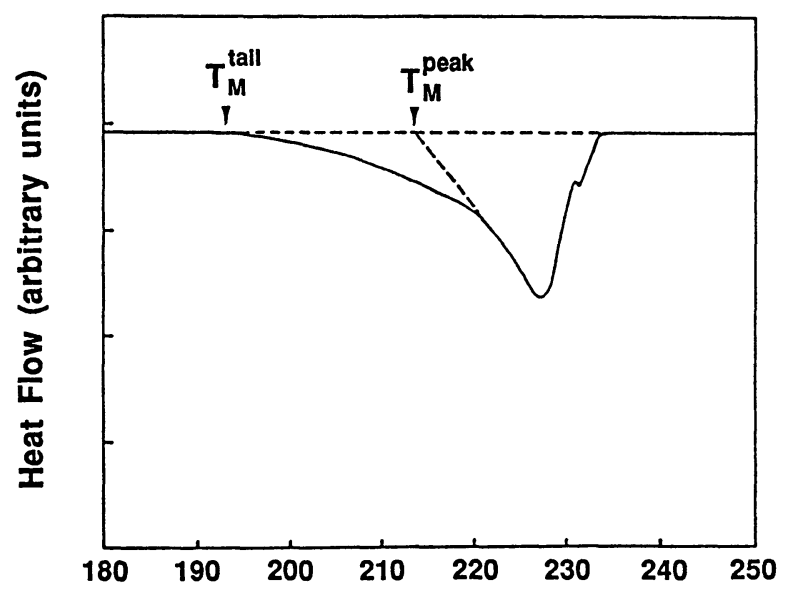

Temperature, $T /{ }^{\circ} \mathrm{C}$

Fig. 8 DSC scan for the melting of Sn in $\mathrm{Sn}-45.5$ vol.\%Ge powder milled $32 \mathrm{~h} . T_{\mathrm{M}}^{\text {peak }}$ and $T_{\mathrm{M}}^{\text {tail }}$ are defined as shown.

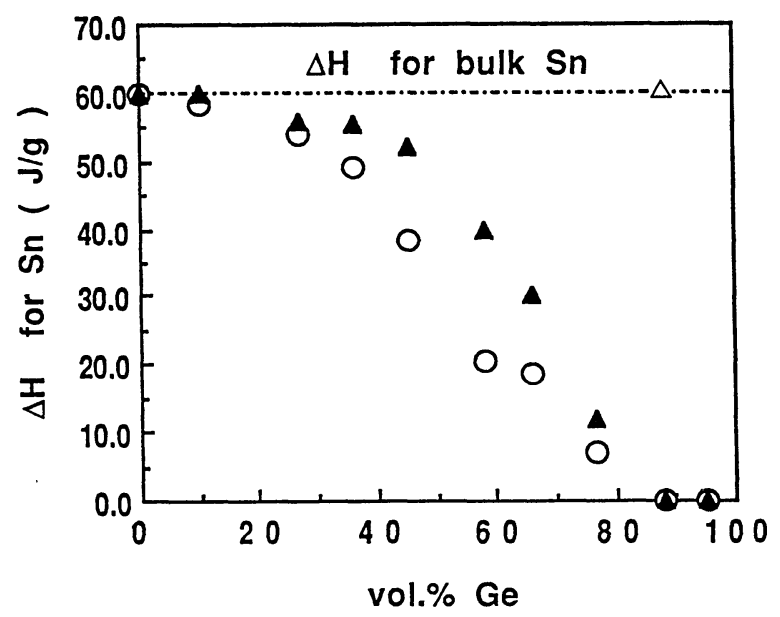

Fig. 9 Enthalpy of fusion of $\mathrm{Sn}$ as a function of vol.\% Ge after a milling time of $32 \mathrm{~h}$. Data for samples cycled once to above $505 \mathrm{~K}$ are also shown. $O$ : as-milled, $\Delta$ : after heating in the DSC to $>505 \mathrm{~K}$; $\triangle$ : unmilled $\mathrm{Sn}-88$ vol. $\% \mathrm{Ge}$.

small as illustrated in Fig. 9. This result was modeled by Turnbull et al. ${ }^{(43)}$ by supposing that the $\mathrm{Sn}$ is distributed between an interfacial and bulk state. The interfacial state is one in which the $\mathrm{Sn}$ is assumed to be in a disordered, possibly amorphous state and coats the Ge particles uniformly to a constant thickness, $d$. The remaining "bulk" Sn is assumed to exhibit the normal enthalpy of fusion. The model accounts for the dependence of $\Delta H_{\mathrm{M}}$ on $V_{\mathrm{Ge}}$ within experimental uncertainty. With the average size of Ge particles $\sim 10 \mathrm{~nm}, d$ is estimated to be $\sim 0.23$ $\mathrm{nm}$, i.e., of the order of the thickness of one $\mathrm{Sn}$ monolayer. Attempts to observe the $\mathrm{Sn}$ interfacial layer by TEM were inconclusive although suggestions of amorphous halos were observed in electron diffraction patterns for samples with $V_{\mathrm{Ge}}>0.81$ near the position where the (101) Sn diffraction ring should appear.

A subsequent ${ }^{119} \mathrm{Sn}$ Mössbauer effect study ${ }^{(44)}$ of the
Ge-Sn system (the samples of Jang and Koch) revealed new insights for the nature of the Sn component which does not exhibit melting in these mechanically milled GeSn powders. Mössbauer spectroscopy measurements reveal two major sites for the $\mathrm{Sn}$ atoms in nanoscale $\mathrm{Ge} / \mathrm{Sn}$ dispersions prepared by ball milling. These are tetragonal $\beta$-Sn and another site termed the " $\mathrm{A}$ " site. The $\beta$-Sn site intensity ratio decreases at the expense of the " $A$ " site intensity ratio with increasing $\mathrm{Ge}$ concentration in the $\mathrm{Ge}_{1-x} \mathrm{Sn}_{x}$ samples. The isomer-shift of the " $\mathrm{A}$ " site and the small/negligible quadruple splitting of this site strongly suggest that it represents $\mathrm{Sn}$ in solid solution in the Ge lattice. This conclusion is in contrast to the previous assumption that $\mathrm{Sn}$ atoms not contributing to the measured enthalpy of fusion in milled Ge/Sn dispersions were in the form of a disordered/amorphous film surrounding the Ge particles. The Mössbauer results point to a large (12-24 at \%) nonequilibrium solid solubility of $\mathrm{Sn}$ in Ge after mechanical milling. The fine nanocrystalline structure (Ge particle diameters $\sim 10 \mathrm{~nm}$ ) is presumably responsible for the enhanced solubilities.

Nanocrystalline composites of $\operatorname{Si}_{1-x} \mathrm{Sn}_{x}(x \leq 0.3)$ were subsequently prepared by mechanical attrition in a shaker mill ${ }^{(45)}$. A marked reduction in the breadth and intensity of the Si X-ray diffraction lines was noted. Substitution of $\mathrm{Pb}$ for $\mathrm{Sn}$ provided an accelerated decrease in the Si line intensities with milling time suggesting that $\mathrm{X}$-ray absorption and/or strain effects are contributing to these observations. TEM studies confirmed the nanocrystalline microstructure inferred from X-ray diffraction and gave no evidence to suggest the occurrence of amorphization.

\section{Nanocrystalline Materials by Ball Milling}

While the recent interest in nanostructured materials was stimulated by the research of Gleiter and co-work$\mathrm{ers}^{(46)}$ on materials produced by the gas-condensation/ vacuum compaction method, other synthesis techniques have been used; for example electrodeposition ${ }^{(47)}$, sputtering ${ }^{(48)}$, and thermochemical routes ${ }^{(49)}$. One of the methods that has received significant attention is mechanical attrition-the ball milling of single or multicomponent powders. Mechanical attrition produces its nanostructures not by cluster assembly but by the structural decomposition of coarser-grained structures as the result of severe plastic deformation.

Much of the systematic research on the evolution of nanocrystalline single phase materials by mechanical attrition has been carried out by W. L. Johnson and co-workers at California Institute of Technology. Our interest in this subject also was stimulated by the ubiquitous appearance of fine nanocrystalline grains at milling times prior to the observation of amorphization by $\mathrm{MM}^{(50)}$ as described in Section V. MM of $\mathrm{Nb}_{3} \mathrm{Sn}$ is an example of the development of a nanocrystalline structure by mechanical attrition prior to amorphization ${ }^{(32)(50)}$. The lattice parameter $a_{0}$ of the $\mathrm{A} 15 \mathrm{Nb}_{3} \mathrm{Sn}$ compound was observed to increase with increasing milling time and then to 
remain constant prior to amorphization. Most (about $80 \%$ ) of the observed expansion occurs as the long-range order parameter $\mathrm{S}$ disappears, i.e. by $1 \mathrm{~h}$ milling time in the Spex mill. That most of the observed lattice parameter expansion is attributable to anti-site chemical disorder is consistent with the lattice parameter increases seen after neutron irradiation. The ordered $\mathrm{Nb}_{3} \mathrm{Sn} \mathrm{A} 15$ lattice with niobium atoms occupying all of the mutually orthogonal chains in the cube faces (i.e. at $01 / 21 / 4,0$ $1 / 23 / 4$ etc.) provides a dense structure with niobium atom nearest-neighbor positions contracted over those in pure niobium. Antisite disordering results in an expansion of the optimum packing of the completely ordered structure. The additional expansion of $a_{0}$ after disordering is complete may be due to the topological disorder associated with the grain boundaries of the nanocrystallites as they develop and their size decreases with milling time.

The fact that plastic deformation can be introduced into nominally brittle $\mathrm{Nb}_{3} \mathrm{Sn}$ by ball milling suggests a large hydrostatic component to the stress state operative during ball milling. Wright ${ }^{(51)}$ has summarized deformation studies on $\mathrm{A} 15$ compounds such as $\mathrm{Nb}_{3} \mathrm{Sn}$ and concludes that plastic deformation is possible near ambient temperature if a high hydrostatic pressure component is present as in hydrostatic extrusion. Plastic deformation is evident from the TEM observations of milled $\mathrm{Nb}_{3} \mathrm{Sn}$ as well as from the work hardening that occurs. Since the powder surface temperatures are believed to increase by no more than $100-200^{\circ} \mathrm{C}$ during milling, the observed deformation must be due to the hydrostatic pressure from the powder trapped between the milling media.

The increase in hardness (about 20\%) on milling of the hard $\mathrm{A} 15 \mathrm{Nb}_{3} \mathrm{Sn}$ intermetallic may be attributed to the reduction in the grain size to nanocrystalline dimensions. The Hall-Petch plot in Fig. 10 is consistent with this assumption. The fact that the major defects observed in the transmission electron micrographs are grain boundaries also supports the suggestion that the observed hardening is due to the reduction of the grain size.

Also plotted in Fig. 10 is data for MM Fe. Jang and $\mathrm{Koch}^{(52)}$ had shown that nanocrystalline $\mathrm{Fe}$ obeys the usual Hall-Petch relationship such that hardness increases as grain size decreases. It is significant that nominally pure iron can be hardened to the same level as that for the hard brittle intermetallic $\mathrm{Nb}_{3} \mathrm{Sn}$. While most hardness studies on nanocrystalline materials exhibit the behavior exhibited in Fig. 10, i.e. Hall-Petch behavior albeit with a much smaller slope to the hardness curve than in conventional materials, there are a number of examples of a transition from grain size strengthening to grain size softening ("inverse" Hall-Petch behavior) at a critical grain size $e^{(53)-(57)}$. Various rationalizations for the grain-size softening transition have been proposed. It may be an artifact of structural or chemical processing defects that modify the microstructure during annealing, for example, porosity changes ${ }^{(56)}$. Alternately, it may be a manifestation of some fundamental modification of the intrinsic deformation mechanisms; changes in grainboundary structure and plastic strain-rate enhancement

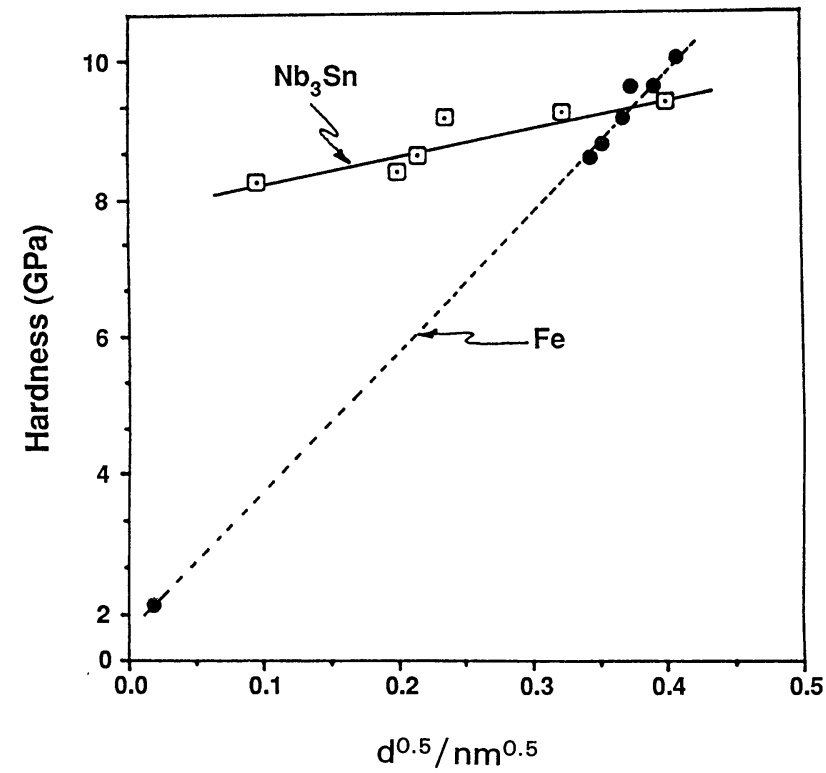

Fig. 10 Variation in hardness with $d^{-1 / 2}$ for $\mathrm{Fe}$ and $\mathrm{Nb}_{3} \mathrm{Sn}$ where $d=$ average grain diameter.

due to diffusional creep have been suggested ${ }^{(53)}$. An alternate model for the possible grain-size softening was presented by Scattergood and $\mathrm{Koch}^{(58)}$. The approach modifies the dislocation-network Hall-Petch model such that a specific prediction of the form of the grain-size softening relation can be obtained. The key feature in the analysis is the fact that dislocation line tension must be size-scale dependent. The grain-size softening transition is identified with a transition from cutting to Orowan bypassing of the network dislocations. The results of the analysis can be expressed as follows:

$$
\begin{aligned}
& H=H_{0}+\frac{k_{\mathrm{H}}}{D^{1 / 2}} ; \quad D \geq D_{\mathrm{c}} \\
& H=H_{0} \frac{k_{\mathrm{H}}}{2 \pi \alpha_{\mathrm{oc}}} \ln \frac{D}{r_{\text {eff }}} \frac{1}{D_{1 / 2}} ; \quad D<D_{\mathrm{c}} .
\end{aligned}
$$

$H_{0}$ is the intrinsic single-crystal hardness $(D \rightarrow \infty), D$ is the grain size, $k_{\mathrm{H}}$ is the Hall-Petch stress intensity parameter (in units appropriate for hardness), $\alpha_{\mathrm{oc}}=1 /$ $2 \pi \ln D_{\mathrm{c}} / r_{\text {eff }}$ with $r_{\text {eff }}=\beta r_{0}$ an effective dislocation corecutoff distance. Note $H_{0}$ and $k_{\mathrm{H}}$ are the same values for both equations and thus $k_{\mathrm{H}}$ determined from data for conventional grain size plots $D>D_{\mathrm{c}}$ should be identical to $k_{\mathrm{H}}$ values determined from fits to the expression for $H$ at $D<D_{\text {c }}$. Remarkable agreement was obtained in this regard for data on several materials, giving some support to the model.

Our current interest in preparation of nanocrystalline materials by mechanical attrition is focused on the questions: 1] how do nanocrystalline structures form during milling? and 2] what determines the thermal stability of such structures? These questions are not totally unrelated since thermal recovery during milling is thought to help determine the final grain size that can be attained. The grain size in a series of nanocrystalline fcc metals pro- 
duced by MM was found to saturate to a minimum value which scales with the melting point of the given element ${ }^{(59)}$. The width of stacking faults in alloys will increase, while the dislocation cross-slip will become more difficult with decreased stacking fault energy (SFE). Thus the alloy with a smaller SFE should exhibit a smaller dynamic recovery effect induced by cross-slip because both dislocation annihilation and the by-passing of obstacles by cross-slip decrease the rate of dislocation storage. Shen and $\mathrm{Koch}^{\left({ }^{(6)}\right)}$ have studied the grain size and hardening effects in nanocrystalline $\mathrm{Cu}-\mathrm{Ni}$ and $\mathrm{Ni}-\mathrm{Co}$ alloys prepared by mechanical attrition.

For $\mathrm{Cu}(\mathrm{Ni})$ solid solutions, SFE increases with increased $\mathrm{Ni}$ content ${ }^{(61)}$ while for $\mathrm{Ni}(\mathrm{Co})$ solid solutions, SFE decreases with increased Co content ${ }^{(62)}$. The SFE of $\mathrm{Cu}_{50} \mathrm{Ni}_{50}$ alloy is about $50 \%$ higher than that of $\mathrm{Cu}^{(61)}$, while the SFE of $\mathrm{Ni}_{50} \mathrm{Co}_{50}$ alloy is approximately one third that of $\mathrm{Ni}^{(62)}$. If one only considers the influence of $\mathrm{SFE}$, the addition of $\mathrm{Ni}$ into $\mathrm{Cu}$ should increase the dynamic recovery of dislocations while the addition of Co into Ni should decrease the dynamic recovery of dislocations. Thus, for $\mathrm{Ni}(\mathrm{Co})$ solid solutions, one may predict a strengthening effect induced by dislocation structure and a distinct decrease of grain size with the increase of Co content. For $\mathrm{Cu}(\mathrm{Ni})$ solid solutions, one may predict the opposite, i.e., an increase of grain size with increased $\mathrm{Ni}$ content. The experimental results indicate, however, that the grain size for various $\mathrm{Ni}(\mathrm{Co})$ solid solutions remains almost constant while that for various $\mathrm{Cu}(\mathrm{Ni})$ solid solutions decreases with increased Ni content, i.e., the composition dependence of the grain size of these nanocrystalline solid solutions does not depend upon the composition dependence of SFE of the conventional solid solutions. The grain size of the nanocrystalline $\mathrm{Cu}-$ $\mathrm{Ni}$ and $\mathrm{Ni}-\mathrm{Co}$ alloys could be inversely correlated with their mechanical hardness and melting temperature. This suggests that a balance between defect creation and recovery is important for determining the grain size.

The thermal stability of nanocrystalline microstructure is of major importance both for hot consolidation of the powders and for any possible elevated temperature applications. Grain growth studies have been conducted on the nanocrystalline intermetallics $\mathrm{Ni}_{3} \mathrm{Al}$ and $\mathrm{Ni}_{3} \mathrm{Si}$. These systems were selected for study because of an EXAFS study $^{(63)}$ which suggested significant segregation at the grain boundaries of nanocrystalline $\mathrm{Ni}_{3} \mathrm{Al}$ but not $\mathrm{Ni}_{3} \mathrm{Si}$. In addition, $\mathrm{Ni}_{3} \mathrm{Al}+0.05$ at. $\% \mathrm{~B}$ was studied since $\mathrm{B}$ readily segregates to the grain boundaries of $\mathrm{Ni}_{3} \mathrm{Al}$. X-ray diffraction line broadening studies were carried out on the high resolution Scintag diffractometer at the High Temperature Materials Laboratory at Oak Ridge National Laboratory. Several methods were used to estimate the grain size and lattice strain. The Warren-Averbach multiple peak method appeared to be most reliable. It was found ${ }^{(64)}$ that the as-milled grain size $(\sim 10 \mathrm{~nm})$ increased rapidly with annealing time at homologous temperatures of 0.4 to 0.55 and then stayed essentially constant for longer times. A plot of grain size vs. annealing temperature normalized by the melting (liquidus) temperature for

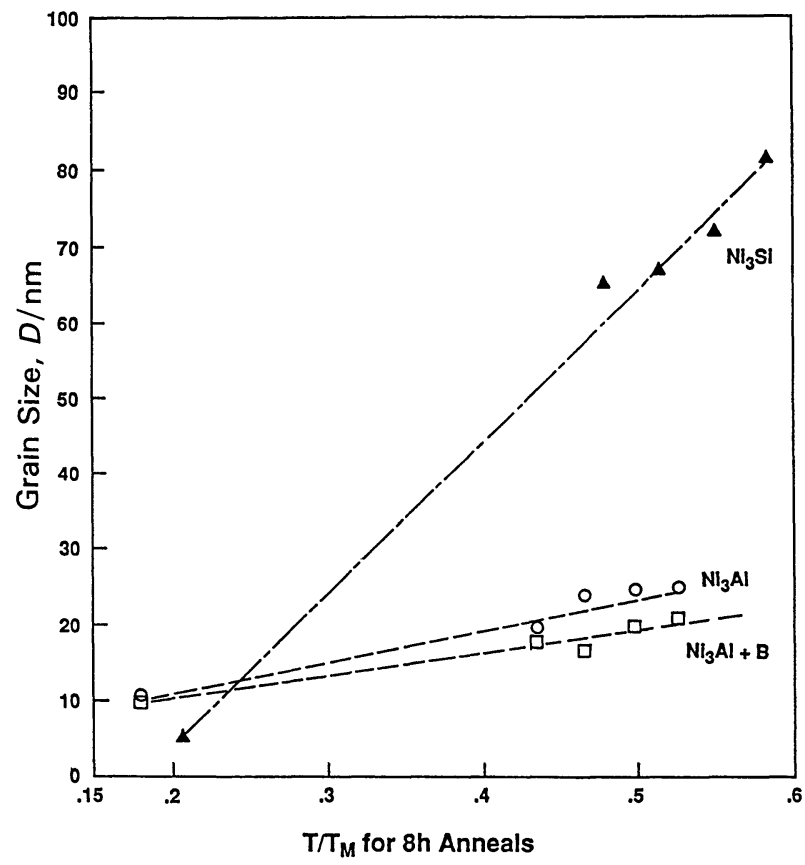

Fig. 11 Average grain size versus normalized annealing temperature (8h anneals) for nanocrystalline $\mathrm{Ni}_{3} \mathrm{Si}, \mathrm{Ni}_{3} \mathrm{Al}$, and $\mathrm{Ni}_{3} \mathrm{Al}+0.02$ at. $\% \mathrm{~B}$.

$8 \mathrm{~h}$ anneals is given in Fig. 11 for nanocrystalline $\mathrm{Ni}_{3} \mathrm{Si}$, $\mathrm{Ni}_{3} \mathrm{Al}$, and $\mathrm{Ni}_{3} \mathrm{Al}+\mathrm{B}$. The nanocrystalline $\mathrm{Ni}_{3} \mathrm{Al}$ and $\mathrm{Ni}_{3} \mathrm{Al}+\mathrm{B}$ show significantly better resistance to grain growth than $\mathrm{Ni}_{3} \mathrm{Si}$. The reason(s) for this behavior is the subject of present research.

\section{Concluding Remarks}

This paper has highlighted research carried out in the author's group at North Carolina State University during the last ten years on metastable materials prepared by mechanical attrition. Most of these studies were devoted to solid state amorphization by either MA or MM. Attention has turned in recent years to the synthesis of nanocrystalline materials. One advantage of mechanical attrition for preparation of such materials is the ability to scale up to tonnage quantities of powder for potential applications. Concerns that need continuing study are the contamination problem and powder consolidation without losing the metastable microstructure.

Ten years ago this sub-field was just starting. Today it is a mature research area. However, due to the complexity of the physics of milling much still remains to be understood. The extension of mechanical attrition to synthesis of non-metallic materials has only begun and many new exciting developments are anticipated.

\section{Acknowledgements}

The author wishes to thank the U.S. National Science Foundation for sustained support of his research in this field by the Division of Materials Research, Dr. Bruce MacDonald, Program Officer, under contracts DMR- 
8318561, DMR-8620394, and DMR-9203479. Work on processing studies and milling of brittle and immiscible materials was supported by the U.S. Office of Naval Research, Dr. Donald Polk, Scientific Officer under grant number N-00014-84K-0253. Finally the author wishes to thank his students who carried out all the experiments.

\section{REFERENCES}

(1) Report of the Panel on Amorphous Materials under the auspices of the Council on Materials Sciences, for the Division of Materials Sciences, U.S. D.O.E., (Dec. 1980), p. 78.

(2) C. C. Koch, O. B. Cavin, C. G. McKamey and J. O. Scarbrough: Appl. Phys. Lett., 43 (1983), 1017.

(3) A. E. Yermakov, E. E. Yurchikov and V. A. Barinov: Fiz. metal. metalloved., 52 (1981), 1184.

(4) A. E. Yermakov, V. A. Barinov and E. E. Yurchikov: Fiz. metal. metalloved, 54 (1982), 1184.

(5) R. L. White: Ph.D. dissertation, Stanford University, (1979).

(6) M. S. Kim and C. C. Koch: J. Appl. Phys., 62 (1987), 3450.

(7) R. B. Schwarz and W. L. Johnson: Phys. Rev. Lett., 51 (1983), 415.

(8) X. L. Yeh, K. Samwer and W. L. Johnson: Appl. Phys. Lett., 42 (1983), 242.

(9) B. T. McDermott and M. S. Thesis: North Carolina State University (1988).

(10) R. M. Davis, B. T. McDermott and C. C. Koch: Metall. Trans., 19A (1988), 2867.

(11) R. B. Schwarz and C. C. Koch: Appl. Phys. Lett., 4 (1986), 146.

(12) D. R. Maurice and T. H. Courtney: Metall. Trans. A, 21 (1990), 289.

(13) C. C. Koch: International J. of Mechanochemistry and Mechanical Alloying, 1 (1994).

(14) R. M. Davis and C. C. Koch: Scripta Metall., 21 (1987), 305.

(15) T. D. Shen and C. C. Koch: Proceedings of ISMANAM-94, Grenoble, France, June 27-July 1, (1994).

(16) B. T. McDermott and C. C. Koch: Scripta Metall., 20 (1986), 669.

(17) M. S. Kim: Ph.D. Thesis, North Carolina State University, (1987).

(18) C. C. Koch and M. S. Kim: J. Physique, 46 (1985), C8, 573.

(19) P. Y. Lee and C. C. Koch: J. Non-Cryst. Solids, 94 (1987), 88.

(20) P. Y. Lee and C. C. Koch: J. Mater. Sci., 23 (1988), 2837.

(21) G. S. Cargill III: Solid State Physics 30, ed. by H. Ehrenreich, F. Seitz and D. Turnbull, Academic Press, NY, (1975), p. 227.

(22) C. N. J. Wagner, T. B. Light, N. C. Halder and W. E. Lukens: J. Appl. Phys., 39 (1968), 3690.

(23) J. S. C. Jang and C. C. Koch: Scripta Metall., 23 (1989), 1805.

(24) C. C. Koch: Mechanical Milling and Alloying, in Materials Science and Technology, ed. R. W. Cahn, P. Haasen, E. J. Kramer, Vol. 15 (volume editor R. W. Cahn), Chapter 5, VCH, Weinheim, (1991), p. 193.

(25) E. Hellstern, L. Schultz, R. Bormann and D. Lewe: Appl. Phys. Lett., 53 (1988), 1399.

(26) R. Bormann: private communication.

(27) M. B. Bever, D. L. Holt and A. L. Titchener: Prog. Mater. Sci., 17 (1973), 1.

(28) J. Koike, D. M. Parkin and M. Nastasi: J. Mater. Res., 5 (1990), 1414.

(29) Y. Seki and W. L. Johnson: Solid State Powder Processing, ed. by A. H. Clauer and J. J. de Barbadillo, TMS, Warrendale, PA,
(1990), p. 287:

(30) H. Bakker and L. M. Di: Proc. Int. Symp. on Mechanical Alloying, ed. by P. H. Shingu, Trans. Tech., (1992).

(31) J. S. C. Jang and C. C. Koch: J. Mater. Res., 5 (1990), 498.

(32) Y. S. Cho and C. C. Koch: Mater. Sci. Eng., A141 (1991), 139.

(33) Y. S. Cho and C. C. Koch: J. Alloys and Compounds, 194 (1993), 287.

(34) G. F. Zhou and H. Bakker: Intermetallics, 2 (1994), 103.

(35) C. H. Lee, M. Mori, T. Fukunaga and U. Mizutani: Japan. J. Appl. Phys., 29 (1990), 540.

(36) Y. Chen, R. Le Hazif and G. Martin: Mater. Sci. Forum, 88-90 (1992), 35.

(37) E. Gaffet and L. Yousfi: Mater. Sci. Forum, 88-90 (1992), 51.

(38) K. Yamada and C. C. Koch: J. Mater. Res., 8 (1993), 1317.

(39) D. Pathak, K. Yamada and C. C. Koch: 2nd Int. Conf. on Mechanical Alloying for Structural Applications, ed. by J. J. de Barbdillo, F. H. Froes, and R. Schwarz, ASM International, Materials Park, Ohio, (1993), p. 205.

(40) S. S. Gross: M. S. Thesis, North Carolina State University, Raleigh, NC USA (1988).

(41) C. C. Koch, J. S. C. Jang and S. S. Gross: J. Mater. Res., 4 (1989), 557.

(42) J. S. C. Jang and C. C. Koch: J. Mater. Res., 5 (1990), 325.

(43) D. Turnbull, J. S. C. Jang and C. C. Koch: J. Mater. Res., 5 (1990), 1731.

(44) P. Boolchand and C. C. Koch: J. Mater. Res., 7 (1992), 2876.

(45) R. T. Leonard and C. C. Koch: Nanostructured Materials, 1 (1992), 471.

(46) H. Gleiter: Nanocrystalline Materials, Prog. Mater. Sci., 33 (1990), 223.

(47) R. O. Hughes, S. D. Smith, C. S. Pande, H. R. Johnson and R. W. Armstrong: Scripta Metall., 20 (1986), 93.

(48) Z. G. Li and D. J. Smith: Appl. Phys. Lett., 55 (1989), 919.

(49) L. E. McCandlish, B. H. Kear and B. K. Kim: Nanostructured Materials, 1 (1992), 119.

(50) C. C. Koch and Y. S. Cho: Nanostructured Materials, 1 (1992), 207.

(51) R. N. Wright: Metall. Trans. A, 8 (1977), 2024.

(52) J. S. C. Jang and C. C. Koch: Scripta Metall. Mater., 24 (1990), 1599.

(53) A. H. Chokshi, A. Rosen, J. Karch and H. Gleiter: Scripta Met., 23 (1989), 1679.

(54) D. K. Kim and K. Okazaki: Mat. Sci. Forum, 88-90 (1992), 553.

(55) G. McMahon and U. Erb: Microstructural Sci., 17 (1989), 447.

(56) G. E. Fougere, J. R. Weertman, R. W. Siegel and S. Kim: Scripta Met. et Mat., 26 (1992), 1879.

(57) K. Lu, W. D. Wei and J. T. Wang: Scripta Metall. Mater., 24 (1990), 2319.

(58) R. O. Scattergood and C. C. Koch: Scripta Metall. Mater., 27 (1992), 1195.

(59) J. Eckert, J. C. Holzer, C. E. Krill, III and W. L. Johnson: J. Mater. Res., 7 (1992), 1751.

(60) T. D. Shen and C. C. Koch: ISMANAM-94, Grenoble, France, June 27-July 1, 1994 to be published by Trans. Tech.

(61) K. Nakajima and K. Numakura: Phil. Mag., 12 (1965), 361.

(62) P. C. J. Gallagher: Metall. Trans., 1 (1970), 2429.

(63) T. Nasu, C. C. Koch, A. M. Edwards and D. E. Sayers: J. NonCrystalline Solids, 150 (1992), 491.

(64) O. M. Spaldon, C. C. Koch and C. R. Hubbard: 123rd TMS Annual Meeting, Feb. 27-March 3, 1994, San Francisco, California. 